\title{
As casas projetadas por J.B. Vilanova Artigas na cidade de São Paulo e a liberdade de sua pesquisa pelos caminhos para a arquitetura*
}

\section{Mauricio Miguel Petrosino}

Arquiteto e Urbanista, mestre pela FAU-USP, professor do curso de graduação em Arquitetura e Urbanismo no SENAC, campus Santo Amaro, Avenida Engenheiro Euzébio Stevaux, 823, Santo Amaro, São Paulo, SP, CEP 04696-000, (11) 5682-7572, petrosinoarq@ ig.com.br

\section{Resumo}

Este artigo comenta a liberdade projetual do Arquiteto João Batista Vilanova Artigas aplicada aos seus projetos de casas construídas na cidade de São Paulo. Apresenta situações da pesquisa pragmática de Artigas na execução dos projetos e obras de "residências unifamiliares" representantes dessa forma de projetar. Ela deve ser entendida como um campo de investigação na prática profissional do arquiteto para essa tipologia de projeto. Analisamos exemplos de obras que poderiam comprovar essa ação projetual, seguindo uma linha de atuação do exercício da arquitetura, numa ordem cronológica do repertório de Artigas e sua busca de possíveis caminhos para a arquitetura.

Palavras-chave: Artigas, liberdade, casa.

\footnotetext{
* Este artigo tem por referência a dissertação de mestrado de título"João Batista Vilanova Artigas - residências unifamiliares: a produção arquitetônica de 1937 a 1981", apresentada em 2009 na Faculdade de Arquitetura e Urbanismo da Universidade de São Paulo.
}

ma das conclusões chegadas após o trabalho de pesquisa no mestrado por mim defendido foi a percepção de uma liberdade projetual presente nos trabalhos das residências unifamiliares na obra de Vilanova Artigas. Liberdade de desenho, de propor a solução pertinente para cada projeto e segundo as possibilidades e demandas de cada um deles e seus clientes. Quando cabível, Artigas aplicava nesses projetos referências a arquitetura norte americana, sobretudo de Frank Lloyd Wright, ou europeia, como de Le Corbusier, por exemplo. Isso foi percebido de forma importante nos 76 projetos residenciais de Vilanova Artigas que foram efetivamente executados

Artigas, como outros profissionais colegas seus engenheiros-arquitetos em início de carreira profissional, buscava atender o mercado imobiliário e da construção civil, no que se refere ao tipo "residências unifamiliares", conforme desejo e programa de necessidades de seus clientes, da destinação das obras, se para venda ou lo- cação ou para moradia do próprio cliente e sua família.

Nos primeiros anos após sua formatura, Artigas também projetou casas de aspectos formais ecléticos, ou, de difícil caracterização formal, como: a residência Henrique Arouche de Toledo, de 1938, no bairro paulistano de Perdizes; a casa José Morganti, de 1938, na Aclimação (Figura 1); a casa Genulfo Máximo de Carvalho, de 1940, na Vila Romana; casa Francisco Franco Teixeira, de 1941, no Ibirapuera, casa Amelie Elisa Celestine Amorim Glover, de 1941, também no Ibirapuera (Figura 2), para citar alguns exemplos. Algumas dessas casas atendiam à demanda do mercado - vale lembrar que, recém-formado, Artigas foi sócio de Duílio Marone, colega de faculdade, com a empresa de construção civil Marone \& Artigas - e, em algumas oportunidades construíram estritamente conforme as necessidades de seus clientes ou à destinação funcional-econômica dessas casas. Isso em nada denigre a imagem do arquiteto. 

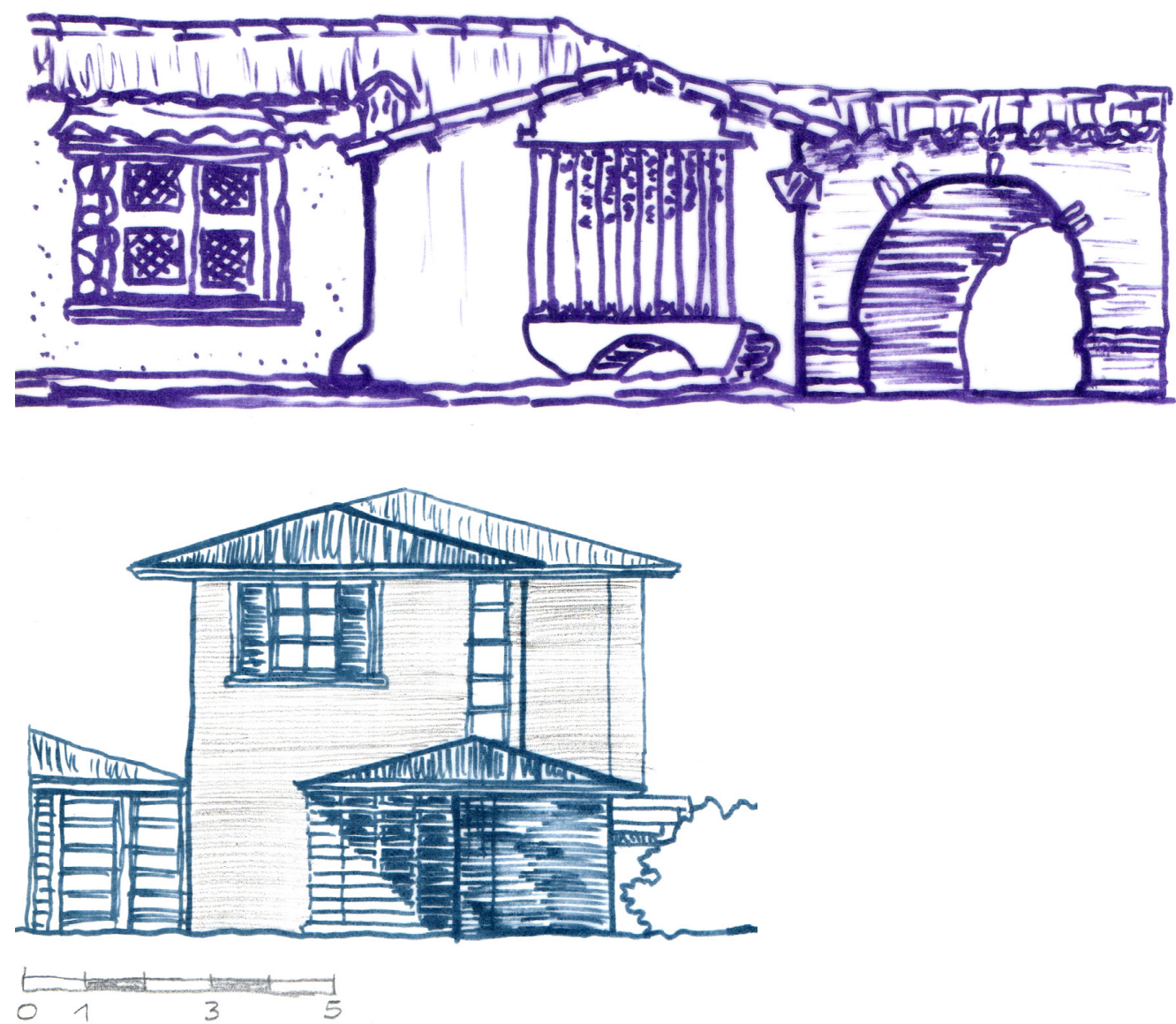

Figura 1: Elevação frontal da casa José Morganti, Artigas, 1938. Fonte: desenho do autor.

Figura 2: Elevação frontal da casa Amelie Elisa C. A. Glover, Artigas, 1941. Fonte: desenho do autor.
Em outras oportunidades, se nota que Artigas utilizou da provável abertura e liberdade de criação e de projetar, permitidas talvez, por uma relação mais próxima com seus clientes, graças a compatibilidades ideológicas, culturais ou outras afinidades que possibilitaram ao arquiteto desenvolver projetos que se pode hoje entender como "ensaios", "laboratórios" da fase "wrightiana" de Artigas, como se fossem pesquisas de repertórios possíveis para elaboração de desenhos de casas, de partidos a serem escolhidos para projetos onde ele pudesse plicar referências aos projetos organicistas de Frank Lloyd Wright.

Na primeira das três fases distintas da produção arquitetônica de Vilanova Artigas, como classificada e aceita pela historiografia e pela maioria dos colegas pesquisadores que se debruçam sobre a obra deste arquiteto paranaense de nascimento, mas paulistano por opção (e talvez dever de ofício) e que compreende o período de 1937 a 1945, pode ser entendida como a fase do pragmatismo projetual, porém, com diversidade nos aspectos formais e com vários exemplos de projetos com evidentes referências à arquitetura do arquiteto norte-americano Frank Lloyd Wright.

Longe de ser uma contradição entre a liberdade de projetar e um frio e calculado pragmatismo na busca das soluções que atendesses a distintos, porém muito próximos no que se refere à essência e conteúdo dos programas de necessidades das casas desse período de produção arquitetônica de Artigas, notamos que, analisados os 76 projetos residenciais construídos em São Paulo, há a pesquisa constante do "como se projetar a habitação unifamiliar" nas diversas possibilidades de desenho e proposta arquitetônica, sem se configurar, obrigatoriamente, na busca de quaisquer estilos, mas, no exercício da liberdade de projetar segundo o entendimento de Artigas a respeito das referências e desejos de seus clientes. Artigas estava atualizado, na medida do possível, com a produção arquitetônica norte americana e europeia, fontes de referência e inspiração para seu pensar a arquitetura nesse contexto dos primeiros oito anos após se tornar 

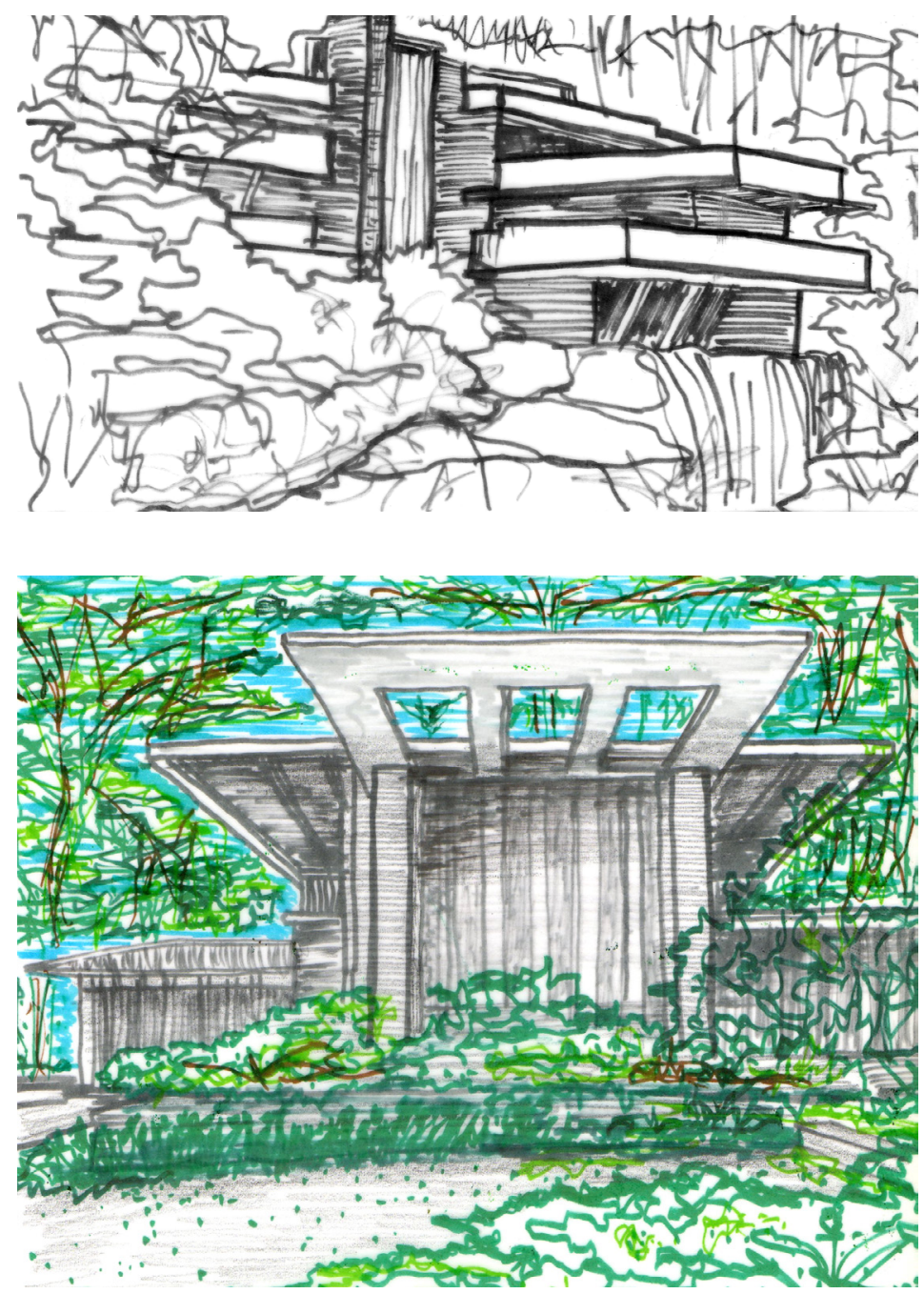

Figura 3 (topo): Casa da Cascata - residência Kaufmann, Frank Lloyd Wright, EUA, 1934-36. Fonte: desenho do autor.

Figura 4: Casa REBHUHN, Frank Lloyd Wright, EUA, 1937. Fonte: desenho do autor. profissional engenheiro-arquiteto. Pode-se imaginar o quão inquietante e desafiador para Artigas, deveria ter sido cada momento de definição do partido de cada um desses projetos, no atendimento aos específicos programas de necessidades e às possibilidades em distintos graus de aplicabilidade das referências ao organicismo de Frank Lloyd Wright, cujo exemplo importante é a Casa da Cascata, ou Edgar J. Kaufmann, em Bear Run, Pensilvânia, EUA, de 1934-36 (Figura 3), às casas de pradaria, como a casa Rebhuhn, em Great Neck Estates, USA, de 1937 (Figura 4) ou ao American System-Built Homes, de 1917, este, um sistema projetado por Wright para Arthur Richards, onde adapta o conceito de casas quadradas a uma planta retangular, como a casa Guy Smith, em Chicago,
USA, de 1917 (ver Irigoyen, Adriana, Wright e Artigas, duas viagens, pag. 128-146).

Essa abertura para a escolha do partido, do desenho, da arquitetura de cada casa a ser proposta para determinado terreno, ou bairro, enfim, para a cidade, em última análise, contextualizam, junto com o momento político-econômico que o Brasil e o Mundo envoltos na Segunda Grande Guerra do século XX, esse espaço-tempo onde a definição de cada projeto expressava a liberdade do arquiteto para desenvolver o projeto, mesmo com as prováveis limitações de utilização de alguns materiais construtivos, em função da escassez ou preços elevados dos mesmos. Nestes casos estaríamos admitindo uma certa "liberdade possível" dada as condições citadas. 

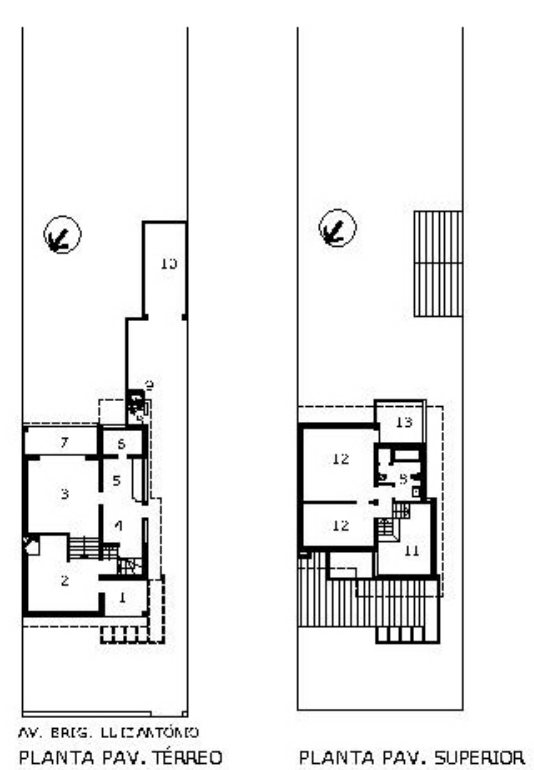

\section{LEGENDA}

1 TERRAÇO DE ACE5SO FRONTAL

2 SALA DE ESTAR

3 SALA DE JANTAR

4 COPA

5 COZINHA

6 DESPENSA

7 TERRAÇO COBERTO

8 SANITÁRIO

9 ÁREA DE SERVIÇO

10 GARAGEM

11 ESTUDIO

12 DORMITORIO

13 TERRAÇO

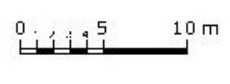

CA5A LUIZ AULICINO

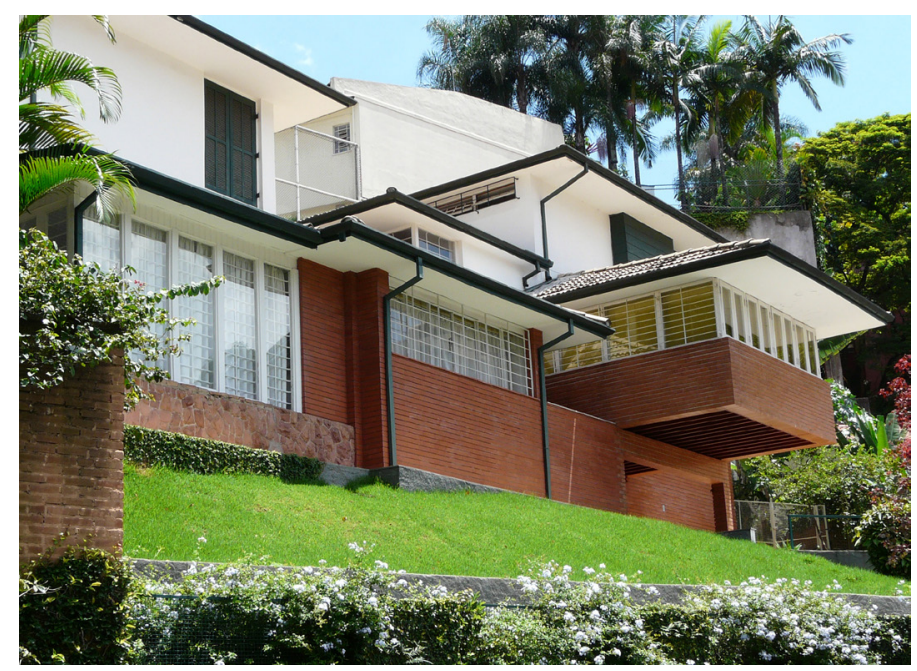

Figura 5 (topo): Casa Luiz Aulicino, planta e corte - Artigas, 1941. Fonte: desenho do autor.

Figura 6: Casa Rio Branco Paranhos, Artigas, 1943. Fonte: fotografia do autor.
É nessa fase que se encontram também as "casas wrightianas", como a residência Luiz Aulicino, de 1941, no Jardim Paulista, (Figura 5), uma clara referência ao "American System-Built Homes"; a casa Roberto Lacaze, de 1941, no Sumaré. Esta última, uma referência às casas organicistas e de pradaria de Wright, graças aos seus aspectos formais e à materialidade escolhida por Artigas para definir o partido arquitetônico e estrutural das alvenarias portantes de tijolos sem revestimento, telhados com telhas de barro, terraço-varanda lateral de acesso.

A Casa Vilanova Artigas - 1, a casinha, de 1942, é um exemplo bem divulgado da produção arquitetônica dessa fase do arquiteto. Situada no bairro de Alto da Boa Vista, também possui referências à arquitetura organicista de Frank Lloyd Wright, e de planta com composição centrífuga, com ambientes que se articulam em torno de um núcleo, um pivô, constituído nesse caso pela lareira e bloco hidráulico de sanitário e cozinha, assim como a residência Rio Branco Paranhos, de 1943, no Pacaembú (Figura 6).

A casa Luiz Antônio Leite Ribeiro - 3, de 1943, no Pacaembú, próxima e na mesma rua da casa Rio Branco Paranhos, apresenta outra investigação de Artigas pelo desenho das casas de pradaria, as "prairies houses", tipo de casas projetadas em determinado momento por Wright, nos Estados Unidos. Nessa casa implantada centralizada no lote, Artigas desenvolveu o projeto numa escarpa 
Figura 7: Casa Benedito Levi, Artigas, 1944. Fonte: fotografia do autor. íngreme dos morros do Pacaembú, com vista para o fundo de vale de mesmo nome do bairro. É uma lição de construção em "pirambeira", que o arquiteto ensinou ao respeitar ao máximo o modelado natural do lote em declive em relação à rua de acesso, fazendo uso mínimo e racional de muros de contenção de concreto ciclóptico que atua estruturalmente para suportar parte da carga da própria casa, que tem o volume das salas em balanço sobre ele, em uma estrutura de concreto armado arrojada para o tipo e época de construção, "soltando" parte da casa do contato com o solo. Percebe-se referências à "Casa da Cascata"; à casa Sturges, em Brentwood Heights, Califórnia, EUA, de 1939, e à casa Tomek, em Riverside, de 1904, todas de Frank Lloyd Wright.

Nem a classificação cronológica consegue exemplificar claramente a compreensão da liberdade projetual que Artigas exercia. Ao mesmo tempo que se pode entender esse fenômeno igualmente como experimentação, dado o caráter intrínseco de pesquisa constante em cada situação de projeto, em função de variações das topografias e localizações dos lotes, do sistema construtivo escolhido para melhor atender cada proposta de projeto, ou a crescente busca por uma identidade nacional da arquitetura que Artigas já se preocupava em encontrar, assim como seu colega de profissão e de partido e ideologia política, Oscar Niemeyer. Nota-se que em 1944, Vilanova Artigas projetou para Benedito Levi uma casa no Jardim Europa (Figura 7) com claríssima interlocução com o formalismo da escola carioca de arquitetura moderna, que, por sua vez, era fortemente referenciada à arquitetura do arquiteto franco-suíço Le Corbusier, calcada num racionalismo estrutural, porém, sem menosprezar intenções formais do desenho dos projetos arquitetônicos. Esta casa do Jardim Europa apresenta estrutura em concreto armado independente das alvenarias e vedos, térreo com pilotis sustentando o pavimento superior, o que permite a planta livre nos pavimentos e as janelas em fita, por exemplo.

Com relação à segunda fase da produção arquitetônica de Vilanova Artigas, compreendida entre os anos de 1946 a 1955, o racionalismo funcional e estrutural da arquitetura de Le Corbusier e a aproximação com a escola carioca de arquitetura moderna exacerbou a característica de Artigas de pesquisar outras possibilidades da arquitetura. Agora, além das orientações pragmáticas e ideológicas nesse período, milita no PCB, Partido Comunista do Brasil - de buscar para o Brasil uma identidade nacional arquitetônica, procura um distanciamento do modelo organicista norte-americano e das referências aos "inglesismos e francesismos" da cultura europeia

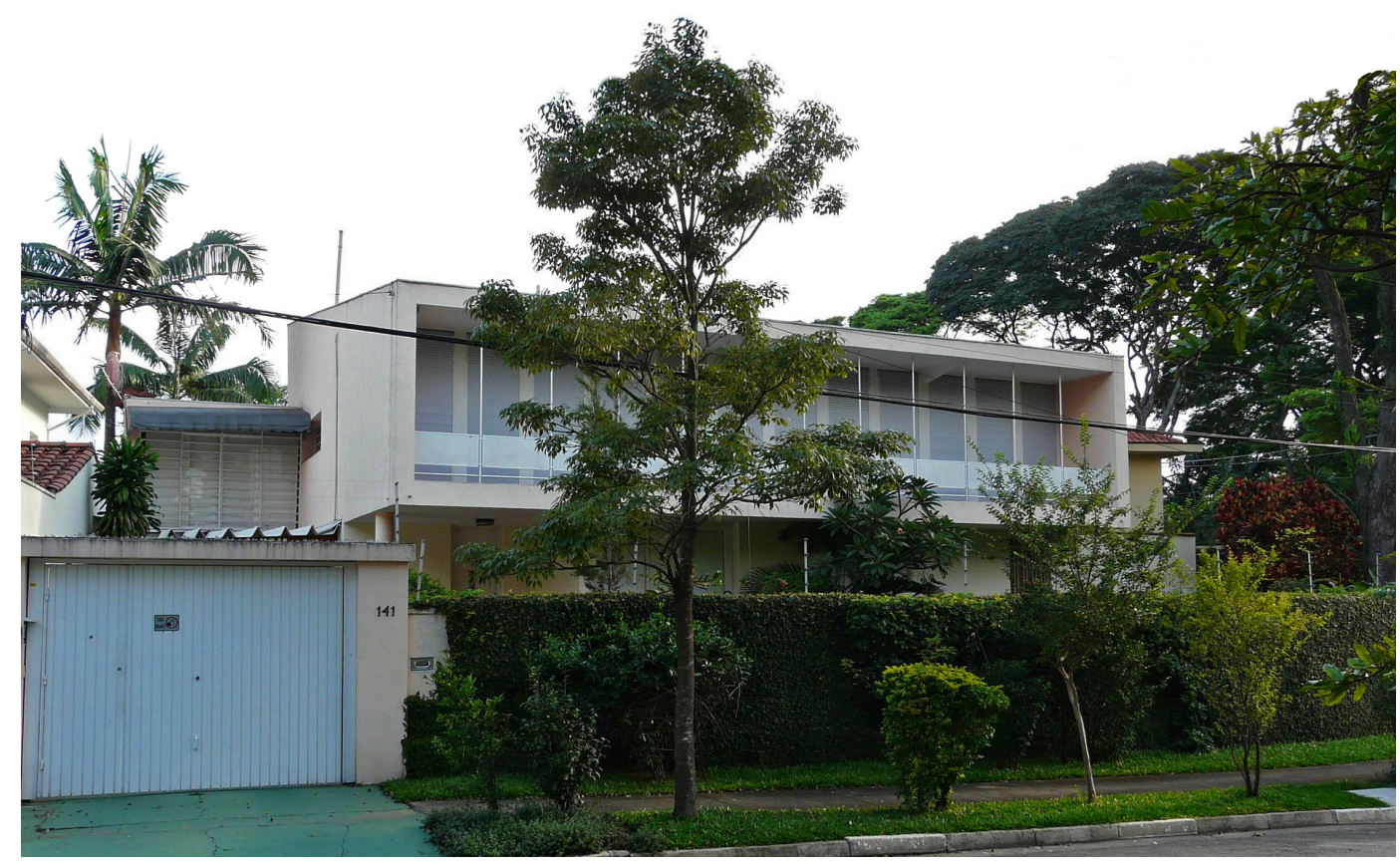




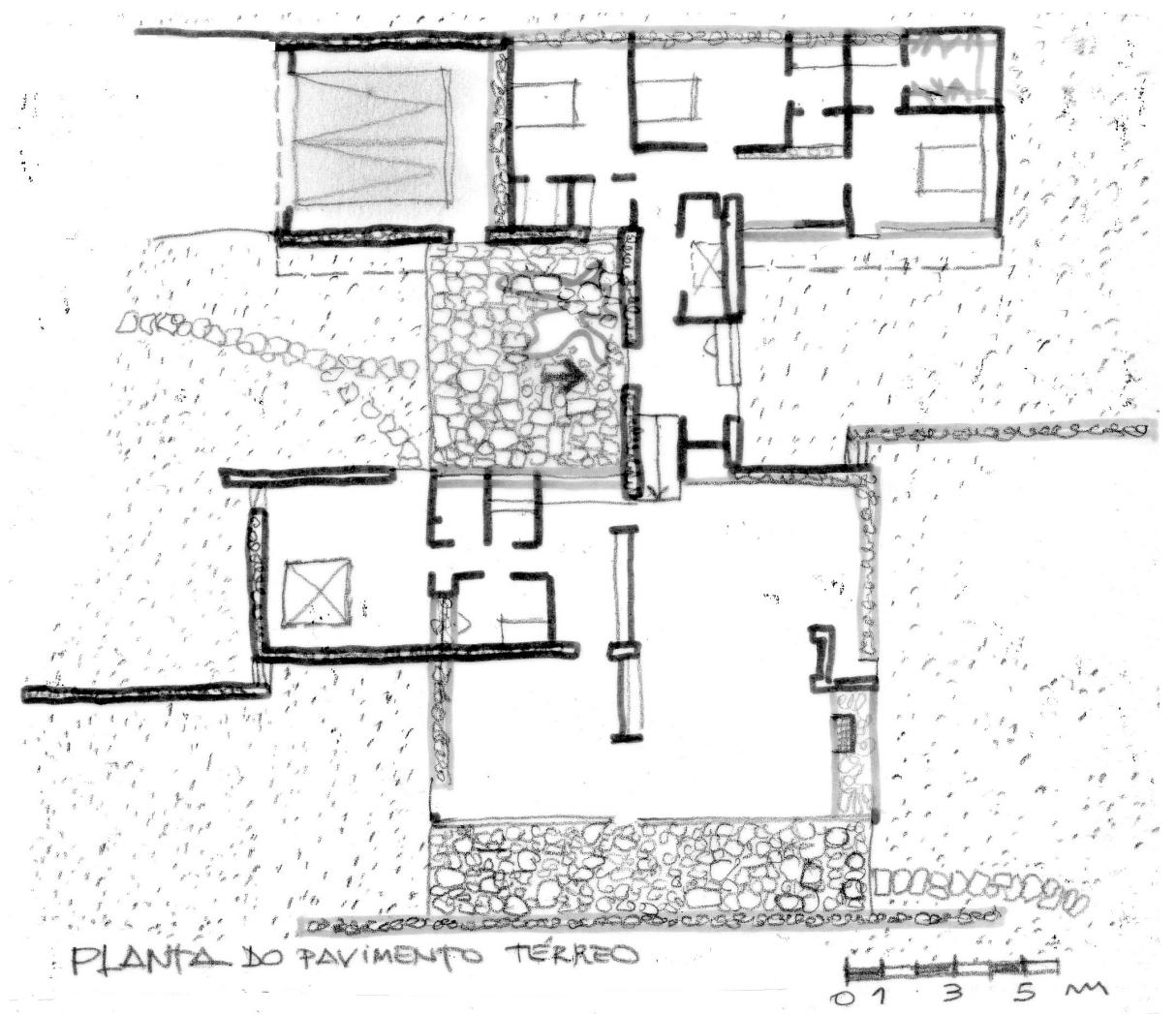

Figura 8: Casa Robinson, Marcel Breuer, EUA, 1948. Fonte: desenho do autor. pré-movimento moderno, mundialmente influente nas artes e arquitetura desde finais do século XIX.

Artigas consegue uma bolsa de estudos nos Estados Unidos na John Simon Guggenheim Memorial Foundation (de outubro/novembro de 1946, por um ano) para aprofundar estudos sobre a arquitetura moderna naquele país. Mesmo já filiado ao PCB (Partido Comunista Brasileiro) e em tempos iniciais de "Guerra Fria", Vilanova Artigas não tem dificuldades em viajar para os Estados Unidos, viajar por diversos estados americanos - uma viagem de "costa a cota" - para conhecer presencialmente exemplos da arquitetura moderna desse país e estabelecer contatos com importantes colegas arquitetos atuantes que tinham seus escritórios na "América", e eram membros do MIT (Massachusetts Institute of Tecnology), como: Alvaar Aalto, Carl Koch, Ralph Rapson e Walter Gropius, dentre outros. Na California tem contato com Richard Neutra que Ihe recomenda visitar alguns exemplos da arquitetura recém construídos neste estado americano.
Artigas provavelmente entrou em contato com Marcel Breuer e sua obra, que seja pelas publicações especializadas, que, em alguns casos, os projetos e/ou obras já incluíam o concreto armado aparente como material estrutura e elemento compositivo de fachadas das edificações ou definidores de espaços internos. Nessa ocasião, é quase certo que Artigas toma ciência dos critérios da "casa bi-nuclear", segundo critérios de distribuição dos ambientes proposta por Marcel Breuer para projetos de habitação, como a casa Robinson, em Massachusetts, EUA (Figura 8). Breuer articula por meio de pátios internos de seus projetos para casas térreas, as áreas de estar e cozinha, da área dos dormitórios. Tanto em planta como na volumetria resultante do projeto era clara a leitura dessa separação funcional dos ambientes, bem como a importância cabal do papel intermediário e articulador dos pátios.

Para Yves Bruand, (BRUAND, Ives. À Margem do Racionalismo: a Corrente Orgânica e o Brutalismo 
Paulista. In Arquitetura Contemporânea no Brasil. São Paulo: Perspectiva, 2005.pp 269-295), 1945 foi o ano da reviravolta na obra de João Batista Vilanova Artigas, no sentido de se buscar alternativas nacionais baseadas em outros modelos, abandonando o que vinha praticando.

Após esse período "sabático" de Artigas nos Estados Unidos que durou até finais de 1947, ele retornou ao Brasil, reorganizou sua visão sobre a arquitetura, fazendo uma revisão crítica de sua produção arquitetônica e participação na vida social brasileira. A sua atuação mais intensa na militância do PCB e a prática de suas orientações e estratégias de atuação profissional e social corroboraram para a revisão de seus trabalhos profissionais até então.

O afinamento e aproximação com a escola carioca de arquitetura moderna e o racionalismo aplicado na arquitetura moderna e a prática da pesquisa nas possibilidades da arquitetura que gostaria de produzir, elevaram o grau pragmático na orientação dele de projetar segundo os preceitos da escola carioca de arquitetura de meados do século $X X$, no entanto, analisando a produção das casas dessa segunda fase de atuação projetual de Artigas, ele exerce a liberdade de projetar segundo suas defesas mais incisivas na atuação social dos indivíduos. Isso aplicado à arquitetura, projeta residências como a Eli Daniel Nassi, em 1948, no Campo Belo e a Hans Victor Trostli, do mesmo ano, no bairro de Sumaré, na capital paulistana.

Em 1949 projetou a primeira casa para Mário Taques Bittencourt, no mesmo bairro do Sumaré e a sua segunda casa, ao lado da "casinha", no mesmo terreno, no bairro do Alto da Boa Vista, em 1949. Esses projetos podem ser entendidos como referên-cias explícitas às casas "bi-nucleares" de Marcel Breuer, embora ainda de maneira preliminar e tímida na casa Eli Daniel Nassi, porém, mais claramente na casa Mario Taques Bittencourt e na Casa Vilanova Artigas 2. As casas de Breuer continham pátios que configuravam mais explicitamente a separação "bi-nuclear" de suas residências para esse partido arquitetônico adotado. Nas casas de Artigas, citadas logo acima, a separação entre os setores sociais e os mais reservados das casas - "íntimos" - é feita por elementos ou ambientes que concentram, por exemplo, instalações hidráulicas, como a cozinha, os sanitários, por exemplo. São ambientes em que o uso também é variável: pode ser compartilhado pelos moradores ou seus convidados, como as cozinhas, ou podem ser utilizados por ambos separadamente, como os sanitários. Esse arranjo dos ambientes adotado nesse partido pode lembrar as "ilhas", ou os núcleos de instalações ao redor das quais se desenvolviam e se orientavam alguns ambientes de projetos residenciais da primeira fase de Artigas, como a casa de Bertha Gift Steiner, de 1940, no bairro Chácara Santo Antônio e a própria casinha, a Casa Artigas I.

Vale lembrar que os projetos da Estação Rodoviária de Londrina (1950) do cinema Autolon e do Edifício Ouro Verde (1948), na mesma cidade paranaense e a residência Heitor de Almeida, de 1949, na cidade paulista de Santos, também são exemplos emblemáticos dessa fase projetual de Vilanova Artigas e auxiliam a contextualizar essas definições de partido arquitetônico do arquiteto.

Outros exemplos da liberdade projetual de Artigas aplicada nos seus trabalhos e que se distinguem formalmente destes últimos citados, porém, conceitualmente fiéis a essa fase de Artigas, são, na cidade de São Paulo: a casa David Rosemberg, de 1950, em Pinheiros e a casa Issac Pechelman, de 1954, no bairro do Pacaembú. São casas de formato predominante como paralelepípedos sobre pilotis que encerram área social sob pavimento superior reservado aos dormitórios. Nos dois casos há volumes menores separados do corpo principal onde se encontram ambientes que requerem instalações hidráulicas ou de serviços.

Vale ressaltar que nesta segunda fase da produção projetual de Artigas, há registros em publicações especializadas, que ele elaborou 69 projetos, sendo 48 deles construídos. Destes, 36 eram projetos de casas e 31 foram construídas. Pode-se afirmar que, com essa produção intensa de projetos residenciais, na sua maioria construídos, se exemplifica e se reforça a tese da pesquisa intensa das possibilidades de partido arquitetônico que Artigas, responsavelmente e com liberdade criativa, praticava nesse tipo de edificações

A partir dessas pesquisas em obras residenciais, Artigas transportou parte de seu repertório para projetos de arquitetura de maiores dimensões, 
como aparece na terceira fase de sua produção arquitetônica nas edificações escolares, os conjuntos habitacionais para o CECAP e outras. Dentre todas as obras, a maior representante e testamento vivo de seus pensar a arquitetura e as possibilidades pedagógicas e didáticas de seus conceitos, formas e espaços criados, como exemplos aplicáveis numa construção de sociedade mais fraterna, transparente e justa, o edifício da FAU-USP, Faculdade de Arquitetura e Urbanismo da Universidade de São Paulo, erguido no campus do bairro do Butantã, zona oeste da capital paulista.

Na terceira e última fase da trajetória profissional de Vilanova Artigas, compreendida entre 1956 e 1984 (Artigas faleceu no mês de janeiro de 1985), o mestre arquiteto paranaense atingiria a maturidade profissional. As preocupações e desejos de encontrar novos caminhos para a arquitetura nacional se intensificam, nem mesmo o desastre sociocultural 1 IROGOYEN, 2002, PP 151153). temporário da ditadura militar no Brasil de 1964 a 1989 que perseguia livres pensadores progressistas, intelectuais e militantes de esquerda no pais apagou as esperanças ou acovardou o discurso humanista e defensor da liberdade plena dos indivíduos e da sociedade brasileira presentes em Artigas.

Boa parte da literatura especializada na área da arquitetura considera os textos críticos, reflexivos e manifestos como Le Corbusier e o Imperialismo, editado originalmente na revista Fundamentos, $n^{\circ}$ 17, de janeiro de 1951 e Os Caminhos da Arquitetura Moderna publicado no número 24 da mesma revista um ano depois, como o registro oficial do pensamento de João Batista Vilanova Artigas com relação às posturas necessárias do profissional arquiteto e da arquitetura frente à sociedade contemporânea e às possibilidades de intervenção profissional e atuação política e social que os arquitetos deveriam trilhar para promover um pais mais justo socialmente e que deveria se inserir num mundo pacificado. Nessa fase, há que se destacar os anos de 1954 e 1955 como de intensa atuação acadêmica e de participação em eventos artísticos como, por exemplo, colaborador na exposição sobre a "Família Artística Paulista", no MAM-SP, em 1954, a despeito de sua baixa produção de projetos de arquitetura.

Nessa terceira fase, Artigas fez 245 projetos, sendo 118 construídos. Do total de projetos, 58 foram referentes a residenciais unifamiliares, destes, 26 (50\%) projetos resultaram em obras realizadas entre 1956 e 1984.

Na década de 1950 Artigas também concentrou esforços na busca da formação - ou formatação - do ensino de arquitetura no Brasil, como parte do programa nacional de reforma do ensino. Ele logrou conformar esse programa de ensino da arquitetura no início da década seguinte no Fórum de 1962, na FAUUSP

Com relação às casas construídas segundo projetos de Artigas nessa terceira fase, há que se notar uma edificação peculiar feita para seu amigo militante do PCB, no bairro do Ibirapuera, em São Paulo, a casa Leo Pereira Lemos Nogueira, de 1959, uma das primeiras edificações em São Paulo a fazer uso da lâmina de água nas lajes de cobertura como sistema de impermeabilização e atenuador da carga térmica para o interior da construção'.

Destacam-se algumas casas desse período que exemplificam e comprovam a busca por soluções diferentes, caminhos possíveis para a arquitetura, calcados na correta interpretação do sitio, da localização e configuração de cada lote as casas seriam erguidas e a mais adequada aplicação e atendimento ao programa de necessidades de cada caso, para cada situação territorial. Podemos afirmar que não houve a menor chance de repetição de desenho ou de organização funcional das plantas em todas as casas projetadas por Artigas desde o início de sua atuação profissional. Em alguns casos há semelhança de partido arquitetônico adotado, como nas casas com coberturas em formato de asas de mariposas, ou as casas com volumes sobre pilotis, mas, para cada uma, um diferente arranjo dos ambientes e espaços criados para atendimento aos programas de necessidades específicos.

A postura de Artigas frente às situações distintas e seu "pragmatismo e rigor projetual", bem conceituado na pesquisa constante que cada oportunidade the oferecia para desenvolver na área do projeto de arquitetura, ia da "provocação" às técnicas de engenharia para atendimento às soluções estruturaisarquitetônicas que propunha, à materialidade do concreto aparente e sua linguagem franca de texturas desenhadas pelas formas, são os mais importantes álibis da plena liberdade projetual de 


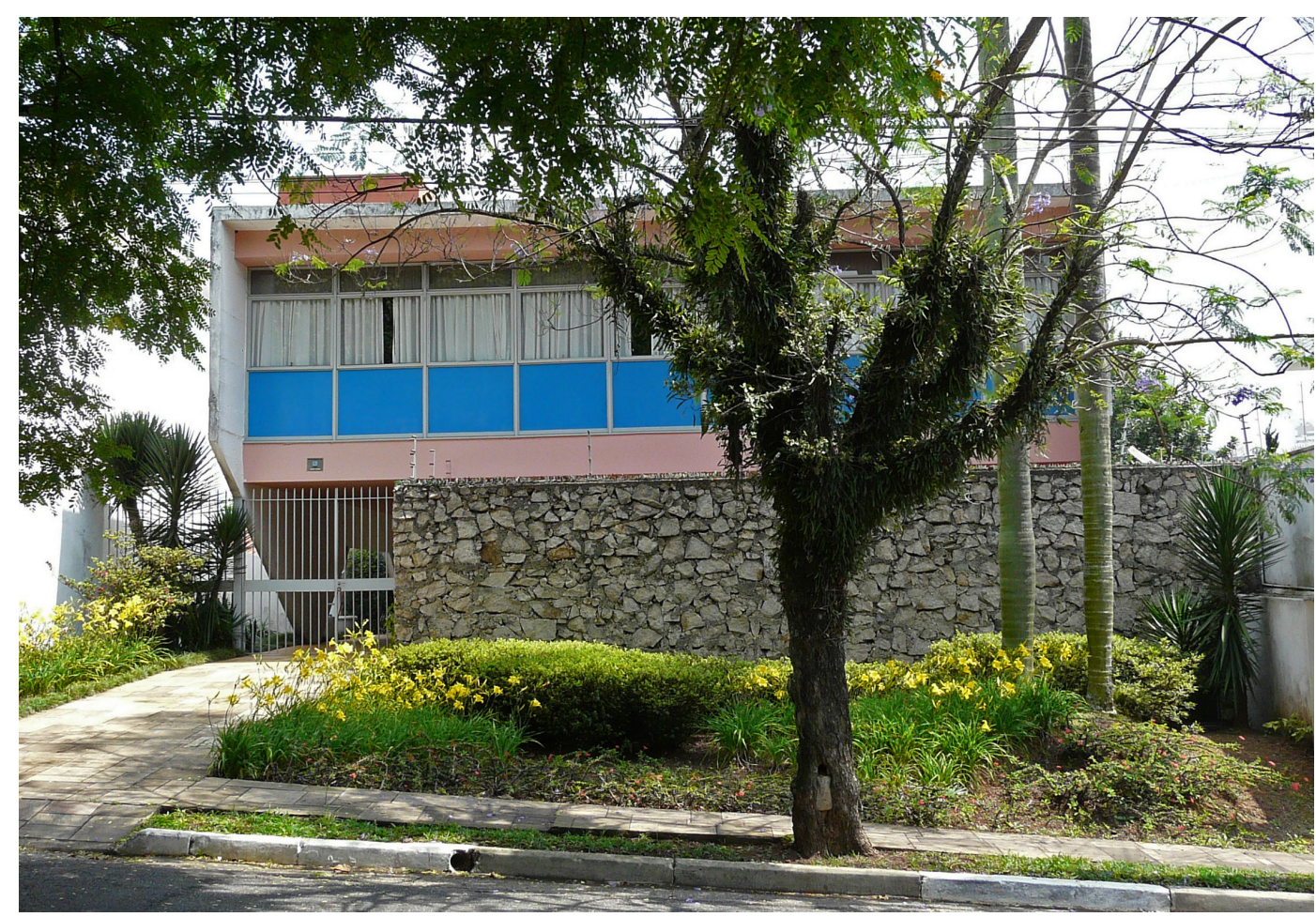

Figura 9: Casa José Mario Taques Bittencourt - 2, Artigas, 1959. Fonte: fotografia do autor.

2 THOMAZ, Dalva. Dissertação de mestrado, FAU-USP, 1997.
Artigas. Liberdade responsável e calculada. Era pesquisa em desenvolvimento desde a prancheta, não sendo seus projetos, aventuras desprovidas de propósitos e sentidos..

A casa Olga Baeta, de 1956, no bairro City Butantã é aceita pela literatura especializada e pela historiografia como a obra que simbolizou o início da terceira e madura fase da produção arquitetônica de Artigas. A crítica especializada a aceita como marco da ruptura de Artigas com o modelo de arquitetura baseado na escola de arquitetura moderna, sobretudo a escola carioca, vigente até então. O emprego do concreto armado é ampliado e, aparente na textura, pois, o arquiteto resolvera pintá-lo na cor branca, talvez para reforçar o discurso da semelhança e referência buscada com tal solução / desenho com as casas de tábuas de madeiras do Paraná, muito presentes em sua memória. Esse recurso de pintar o concreto armado na cor branca Artigas repete nas empenas do edifício pavilhão dos vestiários do São Paulo Futebol Clube, porém, o estádio do Morumbi, anexo, fica em concreto aparente. Atualmente, a estrutura de concreto armado dos vestiários do SPFC se encontra lixada, sem a pintura branca, com acabamento impermeabilizante incolor sobre o concreto aparente. Na casa Olga Baeta, segundo Dalva Thomaz": "encontramos elementos da arquitetura orgânica de Frank Lloyd Wright e do racionalismo de Le Corbusier, na continuidade espacial da sala de jantar versus sala de estar e jardim do pavimento térreo recomposto para ser integrado ao interior da casa que, por sua vez, se constituía (...) nem só Frank Lloyd Wright, nem só Le Corbusier. A partir desta casa Olga Baeta poderíamos afirmar que a prática arquitetônica de Artigas deu um grande salto qualitativo"

A continua pesquisa por novas possibilidades para a arquitetura, por parte de Artigas, quando Ihe aparece a oportunidade de projetar, resultou logo em 1959, no projeto e construção da casa José Mário Taques Bitencourt - 2, a casa dos pórticos que conjuminava a completa junção dos elementos que preconizava serem os componentes de um projeto de arquitetura contemporânea brasileira. Artigas estava gestando, uma "escola paulista de arquitetura". Nessa casa, Artigas conseguiu isolar a estrutura dos volumes internos da estrutura 
da cobertura principal. As empenas laterais em concreto armado aparente chegavam ao solo por meio de quatro pontos de apoio, pilares que eram extensão do desenho peculiar dessas verdadeiras paredes/vigas estruturais (Figura 9).

A casa Rubens de Mendonça, "a Casa dos Triângulos", de 1958, no Sumaré, com o tratamento pictórico das empenas em concreto e outras partes estruturais em concreto, pintado na cor branca, ou externamente com triângulos azuis e brancos, seguindo desenhos sugeridos por seu amigo e artista Francisco Rebolo Gonzáles (1902-1980), quebrou paradigmas com relação à volumetria que se pode passar aos observadores, através de superfícies planas de um volume inserido na paisagem urbana, ao mesmo tempo imponente pela posição e tamanho, mas sem ser grotesco, pesado ou monumental.

A cada residência projetada por Artigas, parece sempre haver uma busca pelo aperfeiçoamento do que foi utilizado em projetos anteriores. Dois projetos residenciais no bairro da Aclimação, em São Paulo, que resultaram na construção de casas, uma em frente à outra e com a utilização do concreto aparente como recurso estrutural e visual, nos demonstram o emprego da mesma linguagem com abordagens distintas. São as casas Ivo Viterito, de 1962 e a Álvaro de Freitas, de 1968.

Em 1966 foi concluída a casa Manuel Mendes André, na Vila Mariana, que é exemplo de implantação do volume paralelepípedo e principal da casa disposto paralelamente à rua de acesso principal e com estrutura mista de concreto e aço, formando desenhos característico de vigas treliças contraventadas que se expõem nas fachadas longitudinais. Esse partido arquitetônico / estrutural não se repete em nenhum outro projeto de Artigas para residências unifamiliares.

Em 1967 é construída a residência Elza Berquó, na Chácara Flora, caracterizada pelo emprego do concreto armado em elementos das fachadas que são ora brises, ora tabeiras, compondo uma linguagem "sui generis" para o arremate alvenarias de fechamento versus cobertura. Nessa casa, Artigas utilizou quatro troncos de árvores como pilares para sustentar o miolo da laje de cobertura, na área do vazio da mesma sobre o pequeno pátio- jardim interno. Isso era o único consentimento de Artigas para expor a estrutura dessa casa, de modo a provocar os especialistas construtores e projetistas de arquitetura: somente quatro apoios visíveis serviam de contato entre a cobertura e o piso.

Outro exemplo, semelhante à casa dos pórticos com relação à independência estrutural entre cobertura e volumes construídos sob ela em atendimento ao programa de necessidades, é dado pela residência Telmo Porto, de 1968, no bairro de Perdizes. Nela, Artigas utiliza-se de toda a largura do terreno e, a partir das divisas laterais do lote, desenvolve empenas enormes em concreto armado aparente que supor-tam a cobertura em laje de concreto armado igualmente aparente, com vigas de dimen-sões consideráveis, para vencer a largura do lote. Internamente, os volumes internos, incluindo as rampas, possuem estrutura independente.

Na casa Martirani, de 1969, no Alto de Pinheiros, Artigas voltou a utilizar pedras naturais como ornamento interno e a aplicar muro de pedras externos, semelhante ao que fizera na casa dos pórticos. É um muro de concreto ciclóptico, que percorre áreas externas e internas da casa, interligando visualmente diversos ambientes, ora configurando-se como base da sustentação do volume principal da casa, ora como demarcador do ambiente de múltiplo uso que era essa garagem de automóveis.

A casa Juvenal Juvêncio, de 1972, no Morumbí (Jardim Guedala), mostra o emprego da estrutura aparente de concreto armado de forma arrojada: vigas treliças longitudinais laterais ao corpo da casa, em concreto armado, apoiadas em apenas 4 pilares e com balanços de 7 metros, vão central de 10 metros que sustentam toda a parte elevada do solo da residência e a laje impermeabilizada da cobertura, com algumas aberturas para permitir a instalação de domus para entrada de luz natural e ventilação permanente de alguns ambientes internos.

Na casa de Geraldo Camargo Demétrio, de 1976، no bairro do Sumaré, Artigas demonstrou mais uma vez como a liberdade de projetar ao interpretar as condicionantes do sitio onde se implanta a 
Figura 10: Casa Geraldo Demétrio, Artigas, 1976. Fonte: fotografia do autor. casa. Nesse caso, um terreno de fortíssimo aclive e pequena área plana na cota mais alta. Artigas inverteu a lógica usual e dispôs os dormitórios em andar intermediário e no superior, na cota do jardim externo dos fundos e da cota mais alta do terreno, Artigas organizou as áreas de estar e de convívio social. As circulações verticais por meio de rampas e escadas internas e externas explicitam a distribuição funcional do programa de necessidades de maneira surpreendentemente atípica (Figura 10).

A casa Mário Taques Bitencourt - 3, concluída em 1981 foi o último projeto de residência unifamiliar que Vilanova Artigas projetou e foi construído. À semelhança da casa Juvenal Juvêncio e Telmo Porto, a estrutura de concreto da cobertura é independente das estruturas dos volumes internos que abrigam o programa de necessidades. Aberturas na laje impermeabilizada da cobertura para implantação de domus é outro recurso aplicado com desenho diferenciado dos anteriores, embora conceitualmente semelhante.

\section{Conclusão}

Percorrendo-se em ordem cronológica, ou não, percebemos nos projetos residenciais do arquiteto João Batista Vilanova Artigas o constante exercício da liberdade projetual na pesquisa de novos elementos, diferentes propostas e possibilidades estruturais e de arquitetura, sempre lastreadas numa postura de conduta projetual densa e precisa. As referências a arquitetos ou questões de arquitetura de outros países foram tratadas por Artigas de maneira pragmá-tica e apropriada. A pesquisa fica evidenciada desde o projeto até a obra concluída, para cada casa. Não se restringe às casas, mas extrapola os limites físicos fundiários de cada lote. Estabelece relações com o entorno imediato e com a cidade de maneira distintas que também refletem a liberdade da busca da melhor e mais conveniente solução para cada programa de necessidades e dados da situação de cada lote.

As leitura e interpretações de cada um dos projetos e obras, também, refletem a liberdade de pensamento e de expressão que foi intentado compreender nesses trabalhos de Artigas.

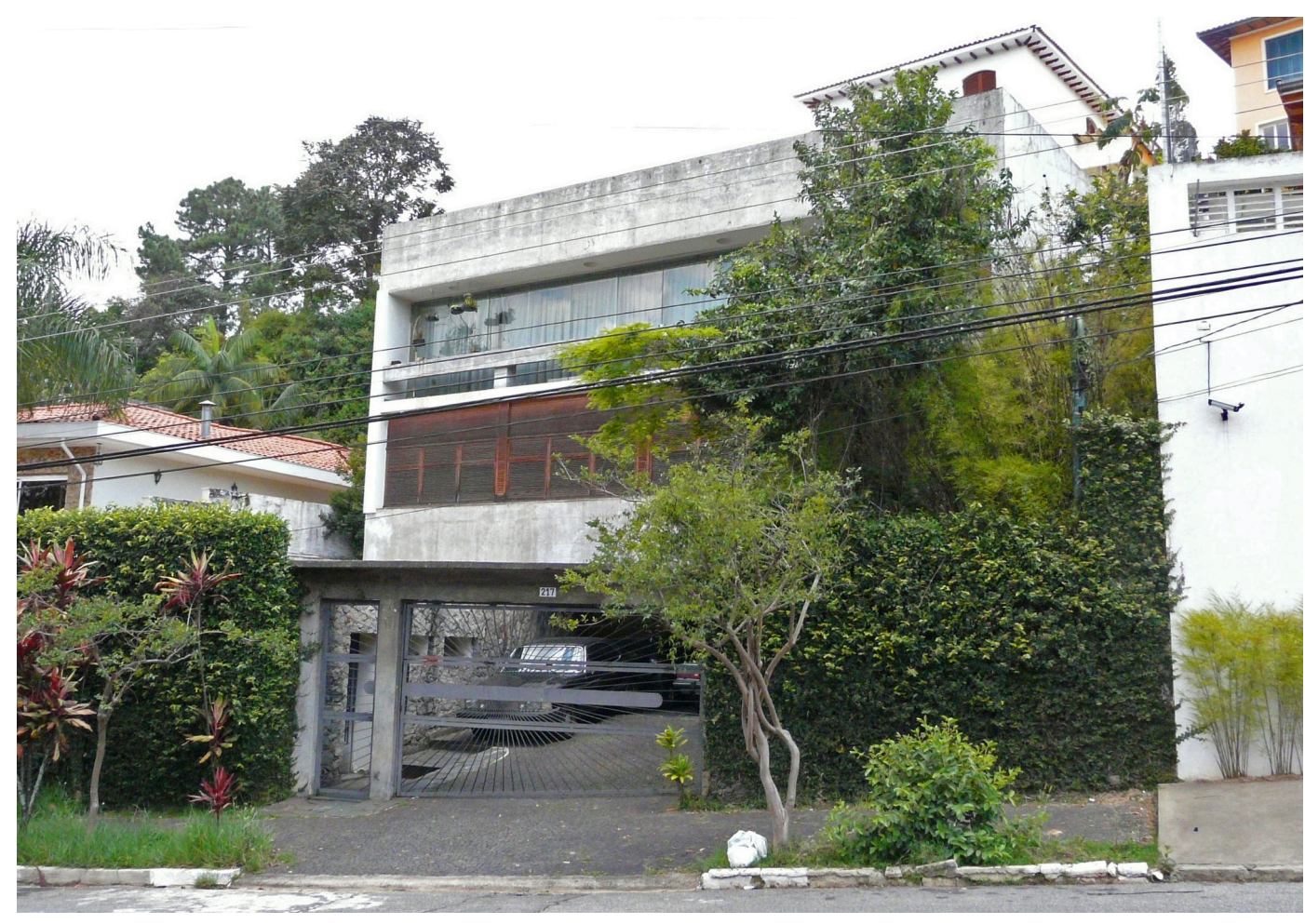




\section{Referências bibliográficas}

ARTIGAS, J.B. Vilanova. Os Caminhos da Arquitetura. São Paulo: Lech-1981;

BRUAND, Ives. À Margem do Racionalismo: a Corrente Orgânica e o Brutalismo. In Arquitetura Contemporânea no Brasil. São Paulo: Ed. Perspectiva, 2005. PP 269-295;

BUZZAR, Miguel Antônio. João Batista Vilanova Artigas: elementos para a compreensão de um caminho da arquitetura brasileira, 1938-1967. $1^{\text {a }}$ ed. - São Paulo. Editora UNESP, Editora SENAC São Paulo, 2014.

IRIGOYEN, Adriana. Wright e Artigas: duas viagens. Ateliê Editorial. São Paulo, 2002;

PETROSINO, Mauricio M. João Batista Vilanova Artigas residências unifamiliares: a produção arquitetônica de 1937 a 1981. Dissertação de Mestrado. FAU_USP, São Paulo, 2009

THOMAS, Dalva E. Um olhar sobre Vilanova Artigas e sua contribuição à Arquitetura Brasileira. Dissertação de Mestrado. FAU_USP, São Paulo, 1997. 